\title{
Subsolidus solution and ionic conductivity of rock-salt structured $\mathrm{Li}_{3+5 \mathrm{x}} \mathrm{Ta}_{1-\mathrm{x}} \mathrm{O}_{4}$ electroceramics
}

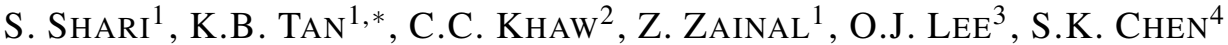 \\ ${ }^{1}$ Department of Chemistry, Faculty of Science, Universiti Putra Malaysia, 43400 Serdang, Selangor, Malaysia \\ ${ }^{2}$ Department of Mechanical and Material Engineering, Lee Kong Chian Faculty of Engineering and Science, Universiti Tunku \\ Abdul Rahman, 43000 Bandar Sg Long Cheras, Malaysia \\ ${ }^{3}$ School of Fundamental Science, Universiti Malaysia Terengganu, 21300 Kuala Terengganu, Terengganu, Malaysia \\ ${ }^{4}$ Department of Physics, Faculty of Science, Universiti Putra Malaysia, 43400 Serdang, Selangor, Malaysia
}

\begin{abstract}
Lithium tantalate solid solution, $\mathrm{Li}_{3+5 \mathrm{x}} \mathrm{Ta}_{1-\mathrm{x}} \mathrm{O}_{4}$ was prepared by conventional solid-state reaction at $925{ }^{\circ} \mathrm{C}$ for $48 \mathrm{~h}$. The $\mathrm{XRD}$ analysis confirmed that these materials crystallized in a monoclinic symmetry, space group $\mathrm{C} 2 / \mathrm{C}$ and $\mathrm{Z}=8$, which was similar to the reported International Crystal Database (ICDD), No. 98-006-7675. The host structure, $\beta-\mathrm{Li}_{3} \mathrm{TaO}_{4}$ had a rock-salt structure with a cationic order of $\mathrm{Li}^{+}: \mathrm{Ta}^{5+}=3: 1$ over the octahedral sites. A rather narrow subsolidus solution range, i.e. $\mathrm{Li}_{3+5 \mathrm{x}} \mathrm{Ta}_{1-\mathrm{x}} \mathrm{O}_{4}(0 \leqslant \mathrm{x} \leqslant 0.059)$ was determined and the formation mechanism was proposed as a replacement of Ta ${ }^{5+}$ by excessive $\mathrm{Li}^{+}$, i.e. $\mathrm{Ta}^{5+} \leftrightarrow 5 \mathrm{Li}^{+}$. Both Scherrer and Williamson-Hall (W-H) methods indicated the average crystallite sizes in the range of $31 \mathrm{~nm}$ to $51 \mathrm{~nm}$. Two secondary phases, $\mathrm{Li}_{4} \mathrm{TaO}_{4.5}$ and $\mathrm{LiTaO}_{3}$ were observed at $\mathrm{x}=0.070$ and $\mathrm{x}=-0.013$, respectively. These materials were moderate lithium ionic conductors with the highest conductivity of $\sim 2.5 \times 10^{-3} \Omega^{-1} \cdot \mathrm{cm}^{-1}$ at $\mathrm{x}=0$, at $0{ }^{\circ} \mathrm{C}$ and $850{ }^{\circ} \mathrm{C}$; the activation energies were found in the range of $0.63 \mathrm{eV}$ to $0.68 \mathrm{eV}$.
\end{abstract}

Keywords: ionic conductivity; subsolidus solution; $\beta$ - $\mathrm{Li}_{3} \mathrm{TaO}_{4}$; electrical properties

\section{Introduction}

Much research attention has been focused on the lithium battery system due to the stringent requirements of portable electronic devices that need high energy density, small memory effect, improved safety and low charge loss during operation. $\mathrm{LiCoO}_{2}$ appears as one example of materials used commercially in the Li-ion battery (LIB) due to its low cost, ease of synthesis and good electrochemical performance. However, a sophisticated and careful fabrication design is important as there could be a potential safety risk under any kind of damage circumstances. Alternatively, $\mathrm{LiFePO}_{4}$ could be used as the cathode material for rechargeable LIB, which offers a good electrochemical stability, remarkable high capacity and good cycling rate capability [1-3].

On the other hand, a wide selection of lithiumbased binary phases containing pentavalent cations,

*E-mail: tankarban@upm.edu.my e.g. $\mathrm{LiTaO}_{3}$ and $\mathrm{LiNbO}_{3}$ have been applied for the optical devices due to their excellent optical properties. Besides that, these phases are also potential ferroelectric materials and their interesting electrical properties are attributed to their cationic displacements, which give rise to a polar crystal structure and dipole reorientation under an applied electric field. These materials could be considered as a superstructure of the $\alpha-\mathrm{Al}_{2} \mathrm{O}_{3}$ corundum, which has a hexagonal structure, R3C [4-6]. On the contrary, the structurally related phases, $\mathrm{Li}_{3} \mathrm{NbO}_{4}$ and $\mathrm{Li}_{3} \mathrm{TaO}_{4}$ have a rock-salt structure with a cationic order of 3:1 over the octahedral sites [7]. Previous research indicated that $\mathrm{Li}_{3} \mathrm{NbO}_{4}$ was successfully prepared by solid-state reaction at $930{ }^{\circ} \mathrm{C}$ for $2 \mathrm{~h}$. Such a phase had a cubic symmetry with a space group of I $43 \mathrm{~m}$. The densified sample demonstrated good microwave dielectric properties with a permittivity, $\epsilon_{\mathrm{r}}$ of 15.8 , quality factor $(\mathrm{Q} \times \mathrm{f})$ value $\sim 55009 \mathrm{GHz}$ and temperature coefficient of resonance frequency $\left(\tau_{\mathrm{f}}\right)$ value about $-49 \mathrm{ppm} /{ }^{\circ} \mathrm{C}[8]$. 
In case of $\mathrm{Ta}$ analogues, $\mathrm{Li}_{3} \mathrm{TaO}_{4}$ phase has a high melting point $\left(\sim 1406{ }^{\circ} \mathrm{C}\right)$, good thermal stability (stable between $0{ }^{\circ} \mathrm{C}$ to $1400{ }^{\circ} \mathrm{C}$ ) and high thermal conductivity $\left(4.351 \mathrm{~W} \cdot \mathrm{m}^{-1} \cdot \mathrm{K}^{-1}\right.$ at $\left.17^{\circ} \mathrm{C}\right)$. Interestingly, $\mathrm{Li}_{3} \mathrm{TaO}_{4}$ exhibits several polymorphs including a low temperature $\beta$-phase $(\mathrm{C} 2 / \mathrm{c})$, high temperature $\alpha$-phase (P2) or intermediate temperature modified phase with a disordered structure. Two phase transitions were found to occur at $900{ }^{\circ} \mathrm{C}$ and $1427{ }^{\circ} \mathrm{C}$, and this was attributed to the transformation of monoclinic $\beta$-phase and $\alpha$ phase, respectively [9-12]. The high temperature $\alpha$-phase was related to the $\beta$-phase by a complex shift series of Ta cations resulting in the symmetry change from $\mathrm{C} 2 / \mathrm{c}$ to $\mathrm{P} 2$.

To date, only limited information is available on the $\mathrm{Li}_{3} \mathrm{TaO}_{4}$ system. Therefore, we have undertaken the study of synthesis and characterization of $\beta-\mathrm{Li}_{3} \mathrm{TaO}_{4}$ subsolidus solution. In this work, the influence of different $\mathrm{Li}$ and Ta concentrations was investigated and discussed systematically in terms of the formation mechanism as well as structural and electrical properties of prepared materials.

\section{Experimental}

$\mathrm{Li}_{3+5 \mathrm{x}} \mathrm{Ta}_{1-\mathrm{x}} \mathrm{O}_{4}(0 \leqslant \mathrm{x} \leqslant 0.059)$ samples were synthesized by conventional solid-state reaction using high purity reagents, i.e. $\mathrm{Li}_{2} \mathrm{CO}_{3}$, (99\%, Aldrich) and $\mathrm{Ta}_{2} \mathrm{O}_{5}$ (99\%, Aldrich). $\mathrm{Ta}_{2} \mathrm{O}_{5}$ was preheated at $600{ }^{\circ} \mathrm{C}$ for $2 \mathrm{~h}$ in order to remove any moisture and impurity before weighing. Stoichiometric amount of oxides were weighed out to yield $\sim 3 \mathrm{~g}$ in total; the mixture was ground homogeneously using an agate mortar and pestle in sufficient amount of acetone prior to further heat treatment. The powdered sample was dried and fired in an alumina (Al) boat at $600{ }^{\circ} \mathrm{C}$ for $2 \mathrm{~h}$ and again fired at the optimized temperature, $925^{\circ} \mathrm{C}$ for two days. Intermediate regrinding was performed to bring fresh surface for a complete reaction. The phase purities of the prepared samples were examined using an automated Shimadzu X-ray diffractometer (XRD) 6000 with $\mathrm{CuK} \alpha$ radiation at scan rate of $2^{\circ} / \mathrm{min}$ over the $2 \theta$ range of $10^{\circ}$ to $70^{\circ}$. The lattice parameter refinement was performed by Checkcell software using the data collected at a scan rate of $0.1 \% \mathrm{~min}$.

For the electrical properties measurement, the pellets of the single phase samples measuring $8 \mathrm{~mm}$ diameter and $\sim 1.0 \mathrm{~mm}$ to $2.0 \mathrm{~mm}$ thickness were prepared using a stainless steel die. Sufficient amount of powder was added, cold pressed at the applied load $\sim 4$ tonnes using a hydraulic press and the resulting pellets were fired at $925^{\circ} \mathrm{C}$ for $24 \mathrm{~h}$. The opposite faces of the densified pellets were coated with gold paste and dried in a furnace from $200{ }^{\circ} \mathrm{C}$ to $600{ }^{\circ} \mathrm{C}$ at a heating rate of $1{ }^{\circ} \mathrm{C} / \mathrm{min}$. The pellet with gold electrodes was attached to a conductivity jig and then inserted into a temperature-controlled tube furnace. The electrical data were collected using a Hewlett Packard LF AC impedance analyzer, HP4192A in the frequency range of $5 \mathrm{~Hz}$ to $13 \mathrm{MHz}$ over a heat-cool cycle. The measurements were taken in the temperature range of $27{ }^{\circ} \mathrm{C}$ to $900{ }^{\circ} \mathrm{C}$ with $50{ }^{\circ} \mathrm{C}$ interval and $20 \mathrm{~min}$ equilibrium time. The impedance data were normalized by the geometric factor (area/thickness; $\mathrm{cm}^{-1}$ ) and corrected for the stray capacitance of the conductivity jig. The thermal properties of the prepared samples were investigated by differential thermal and thermogravimetric analyses (PerkinElmer, STA 6000) over the temperature range of $50{ }^{\circ} \mathrm{C}$ to $1000{ }^{\circ} \mathrm{C}$ in a heatcool ramp at $10{ }^{\circ} \mathrm{C} / \mathrm{min}$ under nitrogen atmosphere. The surface morphologies of the samples were examined by scanning electron microscopy (JOEL, JSM 6400) and the grain size distribution was determined by ImageJ software. The structural information was obtained by Fourier transform infrared spectroscopy (PerkinElmer, 100 series). Meanwhile, the elemental analyses were conducted by inductive coupled plasma-atomic emission spectroscopy (ICP-OES, PerkinElmer Optima 2000DV) using sample triplicates.

\section{Results and discussion}

\subsection{Phase formation and solid solution mechanism}

Fig. 1 shows the XRD patterns of the $\mathrm{Li}_{3+5 \mathrm{x}} \mathrm{Ta}_{1-\mathrm{x}} \mathrm{O}_{4}(0 \leqslant \mathrm{x} \leqslant 0.059)$ solid solution 
synthesized by conventional solid-state reaction at $925{ }^{\circ} \mathrm{C}$ for $48 \mathrm{~h}$. All the characteristic peaks belonging to the monoclinic $\beta-\mathrm{Li}_{3} \mathrm{TaO}_{4}$ are fully indexed based on a space group, $\mathrm{C} 2 / \mathrm{c}$, International Crystal Diffraction Data (ICDD), No. 98-0067675. The refined lattice parameters were found to be in the range 8.4818 (6) $\AA \leqslant a \leqslant 8.5035$ (4) $\AA, 8.4888$ (4) $\AA \leqslant \mathrm{b} \leqslant 8.5020$ (3) $\AA$ and 9.3208 (7) $\AA \leqslant c \leqslant 9.3426$ (5) $\AA$, respectively. At higher Li content, i.e. $\mathrm{x}=0.070$, a secondary phase, $\mathrm{Li}_{8} \mathrm{Ta}_{2} \mathrm{O}_{9}$ (ICDD No. 46-0093) is observed, whereas $\mathrm{LiTaO}_{3}$ (ICDD No. 87-2461) is found below solid solution range, i.e. $x=-0.013$ (inset of Fig. 1). It is worthwhile noting that the $\beta-\mathrm{Li}_{3} \mathrm{TaO}_{4}$ has a random distribution of univalent and pentavalent cations according to the cationic ratio of $3: 1$ within the rock-salt structure. The $\mathrm{Li}^{+}$and $\mathrm{Ta}^{5+}$ cationic sub-lattices comprise of the edge-sharing $\mathrm{LiO}_{6}$ and $\mathrm{TaO}_{6}$ octahedra; in particular, the chains of the edge-sharing $\mathrm{TaO}_{6}$ are created and oriented parallel to the c-axis. However, the $\mathrm{TaO}_{6}$ octahedra are distorted, as the cis-edge-sharing oxygenoxygen distances are significantly shorter than the remaining $\mathrm{O}-\mathrm{O}$ ones [13]. Here, we propose the solid solution formation mechanism as a replacement of single $\mathrm{Ta}^{5+}$ by five interstitial $\mathrm{Li}^{+}$using the general formula, $\mathrm{Li}_{3+5 \mathrm{x}} \mathrm{Ta}_{1-\mathrm{x}} \mathrm{O}_{4}$. Considering a small difference between the ionic radii of $\mathrm{Li}^{+}$ $(0.76 \AA)$ and $\mathrm{Ta}^{5+}(0.64 \AA)$ in the 6-fold coordination, the lattice parameter is found to change insignificantly and such linear variation supports the Vegard law (Fig. 2). In other words, the incorporation of higher $\mathrm{Li}$ content leads to a comparable unit cell within $\mathrm{Li}_{3+5 \mathrm{x}} \mathrm{Ta}_{1-\mathrm{x}} \mathrm{O}_{4}$ solid solution. This suggests that the ionic size plays an important role in the crystallo-chemical change especially in the absence of any distinct phase change.

On the other hand, the elemental concentration analyses of the $\mathrm{Li}_{3+5 \mathrm{x}} \mathrm{Ta}_{1-\mathrm{x}} \mathrm{O}_{4}(0 \leqslant \mathrm{x} \leqslant 0.059)$ samples are summarized in atomic percentage in Table 1 . The oxygen concentration is determined based on the differences in the metal cations. The determined compositions have been found in a good agreement with the theoretical values, thus, confirming the correct stoichiometry of the prepared samples.

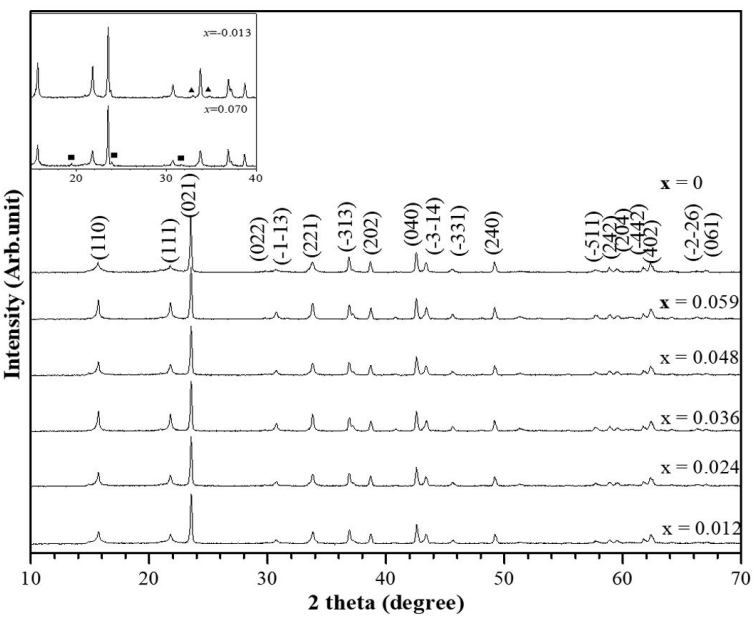

Fig. 1. XRD patterns of the prepared $\mathrm{Li}_{3+5 \mathrm{x}} \mathrm{Ta}_{1-\mathrm{x}} \mathrm{O}_{4}$ $(0 \leqslant x \leqslant 0.059)$ solid solutions: $\mathrm{LiTaO}_{3}(\boldsymbol{\Delta})$ and $\mathrm{Li}_{8} \mathrm{Ta}_{2} \mathrm{O}_{9}(\mathbf{m})$.

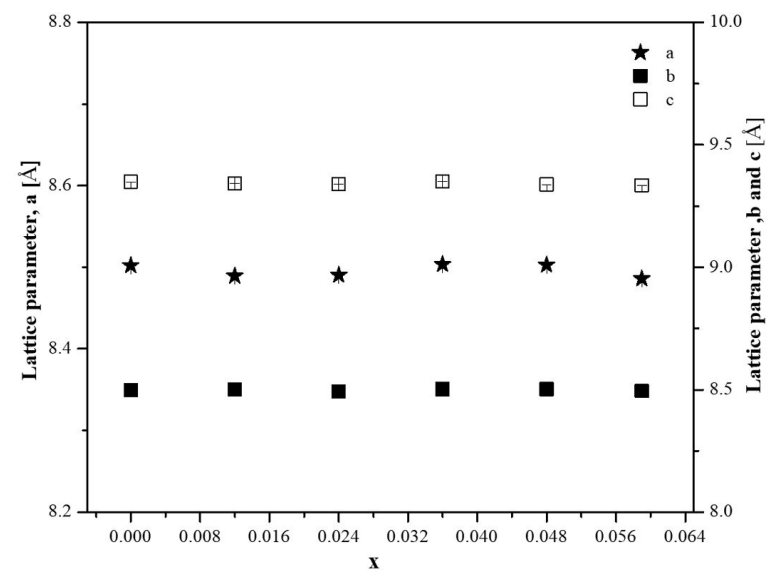

Fig. 2. Variation of lattice parameters $(a, b$ and $c)$ as a function of composition of $\mathrm{Li}_{3+5 \mathrm{x}} \mathrm{Ta}_{1-\mathrm{x}} \mathrm{O}_{4}(0 \leqslant$ $x \leqslant 0.059)$.

\subsection{Crystallite size and surface morphol- ogy studies}

Both Scherrer and Williamson-Hall (W-H) methods have been used to calculate the crystallite sizes and these values appear to be highly correlated. The determined crystallite sizes are found to be in the range of $37 \mathrm{~nm}$ to $53 \mathrm{~nm}$. The average crystallite size of the $\mathrm{Li}_{3+5 \mathrm{x}} \mathrm{Ta}_{1-\mathrm{x}} \mathrm{O}_{4}$ subsolidus solution has been calculated using the DebyeScherrer formula:

$$
D=k \lambda / \beta \cos \theta
$$


Table 1. Elemental analysis of the $\mathrm{Li}_{3+5 \mathrm{x}} \mathrm{Ta}_{1-\mathrm{x}} \mathrm{O}_{4}$ solid solution.

\begin{tabular}{llll}
\hline$x$ & \multirow{2}{*}{ Element } & \multicolumn{2}{c}{ Atomic percentage [\%] } \\
\cline { 3 - 4 } 0 & $\mathrm{Li}$ & 6.27 & Cxperimental \\
\hline \hline \multirow{2}{*}{0.012} & $\mathrm{Ta}$ & 54.47 & $54.21 \pm 0.0$ \\
& $\mathrm{O}$ & 39.26 & 39.32 \\
& $\mathrm{Li}$ & 6.44 & $6.14 \pm 0.26$ \\
& $\mathrm{Ta}$ & 54.16 & $53.64 \pm 0.44$ \\
0.024 & $\mathrm{O}$ & 39.4 & 40.22 \\
& $\mathrm{Li}$ & 6.61 & $6.42 \pm 0.11$ \\
& $\mathrm{Ta}$ & 53.86 & $53.80 \pm 0.5$ \\
0.036 & $\mathrm{O}$ & 39.53 & 39.78 \\
& $\mathrm{Li}$ & 6.78 & $6.64 \pm 0.06$ \\
& $\mathrm{Ta}$ & 53.56 & $53.57 \pm 0.34$ \\
0.048 & $\mathrm{O}$ & 39.66 & 39.79 \\
& $\mathrm{Li}$ & 6.94 & $6.80 \pm 0.02$ \\
& $\mathrm{Ta}$ & 53.27 & $53.10 \pm 0.02$ \\
0.059 & $\mathrm{O}$ & 39.79 & 40.10 \\
& $\mathrm{Li}$ & 7.11 & $7.27 \pm 0.08$ \\
& $\mathrm{Ta}$ & 52.98 & $52.75 \pm 0.40$ \\
\hline
\end{tabular}

whereas for the $\mathrm{W}-\mathrm{H}$ method, the strain-induced broadening and crystallite size have been deduced by:

$$
\beta \cos \theta=k \lambda / D+4 \varepsilon \cdot \sin \theta
$$

where $\mathrm{D}$ is the crystallite size, $\mathrm{k}$ is a constant $=0.9$, $\lambda$ is the wavelength of $\mathrm{Cuk} \alpha$ radiation, $\beta$ is the full width at half maximum (FWHM, in rad), $\theta$ is the diffraction angle and $\epsilon$ is the internal strain. The five intense diffraction planes have been chosen for the peak broadening analysis (Fig. 3). The crystallite size and internal strain values calculated from the y-intercept and gradient are portrayed in Fig. 4. These results were then compared with the grain sizes determined by SEM analysis in Table 2. It can be concluded that the internal strain values are relatively low in the range of 0.00013 to 0.00065 , which shows a good structural stability. In general, the lattice strain depends strongly on the coordination number, chemical bond length, defects or the amount of substitutions in the samples, wherein all these factors could have a significant influence to the overall structure [14]. In this study, the low strain values indicate a low degree of structural distortion or there is little likelihood of crystal imperfection. In addition, all the metal cations are expected to bond comfortably with oxide anions in their preferred coordination environments [15].

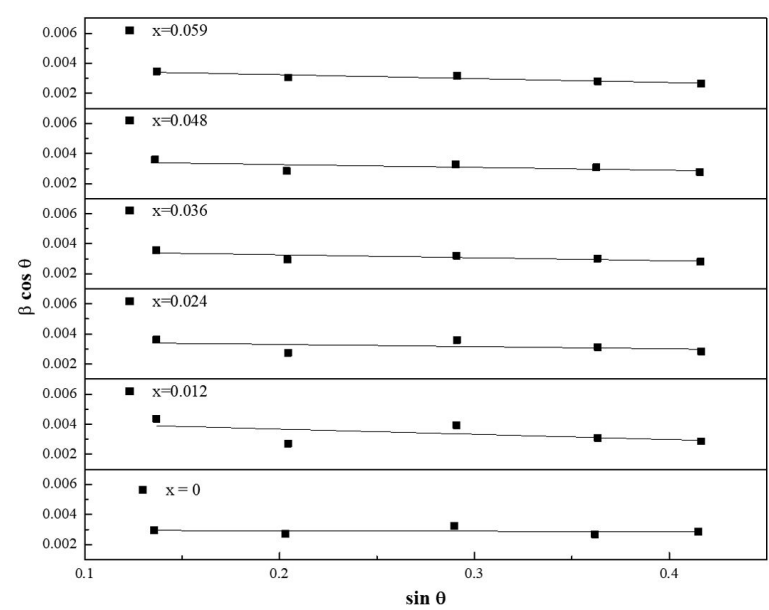

Fig. 3. Williamson-Hall plots of the $\mathrm{Li}_{3+5 \mathrm{x}} \mathrm{Ta}_{1-\mathrm{x}} \mathrm{O}_{4}$ solid solutions. 


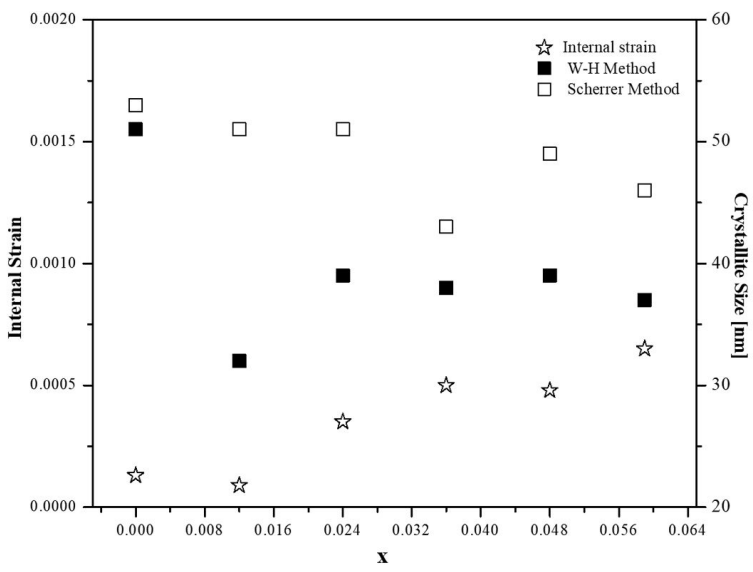

Fig. 4. Comparison between the crystallite sizes calculated by Scherrer and Williamson-Hall method, and the internal strain of the $\mathrm{Li}_{3+5 x} \mathrm{Ta}_{1-x} \mathrm{O}_{4}$ solid solution as a function of $\mathrm{x}$.

Fig. 5 shows the SEM micrographs of the $\mathrm{Li}_{3+5 \mathrm{x}} \mathrm{Ta}_{1-\mathrm{x}} \mathrm{O}_{4}$ solid solutions $(0 \leqslant \mathrm{x} \leqslant 0.059)$ sintered at $925{ }^{\circ} \mathrm{C}$. These samples have relative densities more than $80 \%$ and their microstructures are generally consisted of polyhedral grains. As Li content increases, a broad grain size distribution is observed in the histograms (Fig. 6) and this shows that the grain sizes of the $\mathrm{Li}_{3+5 \mathrm{x}} \mathrm{Ta}_{1-\mathrm{x}} \mathrm{O}_{4}$ solid solution $(0 \leqslant x \leqslant 0.059)$ are in the range of $0.95 \mu \mathrm{m}$ to $1.75 \mu \mathrm{m}$. It indicates that the larger grains contain several to hundreds of smaller crystallites. On the other hand, a gradual increase is found in the grain size and pellet density with increasing Li content. Such a phenomenon could be due to the lower crystallization temperature, i.e. lithium carbonate has a lower melting point of $723{ }^{\circ} \mathrm{C}$ compared to that of tantalum oxide at $1872{ }^{\circ} \mathrm{C}$ [16]. The grain size and pellet density of each composition are plotted as a function of $x$ in Fig. 7. As the lithium content increases, the density of the pellets increases due to the formation of larger grains. The change in grain size is expected to have a significant impact on the activation energy and electrical conductivity. In order to gain further insight into crystallo-chemical properties of the $\mathrm{Li}_{3+5 x} \mathrm{Ta}_{1-\mathrm{x}} \mathrm{O}_{4}$; solid solution, TEM measurements were performed to estimate the sizes and morphology of the sample grains [17]. The particles show clear and nearly spherical shapes with quadrangle edges. These samples show a considerable degree of agglomeration and the average particle sizes are found to be in the range of $36 \mu \mathrm{m}$ to $134 \mu \mathrm{m}$ (Fig. 8).

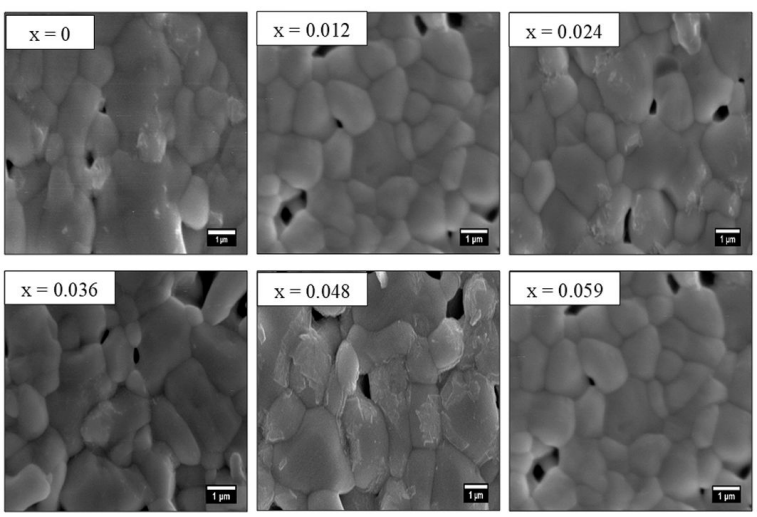

Fig. 5. SEM micrographs of the $\mathrm{Li}_{3+5 \mathrm{x}} \mathrm{Ta}_{1-\mathrm{x}} \mathrm{O}_{4}$ solid solution $(0 \leqslant x \leqslant 0.059)$ at $\times 5000$ magnification.

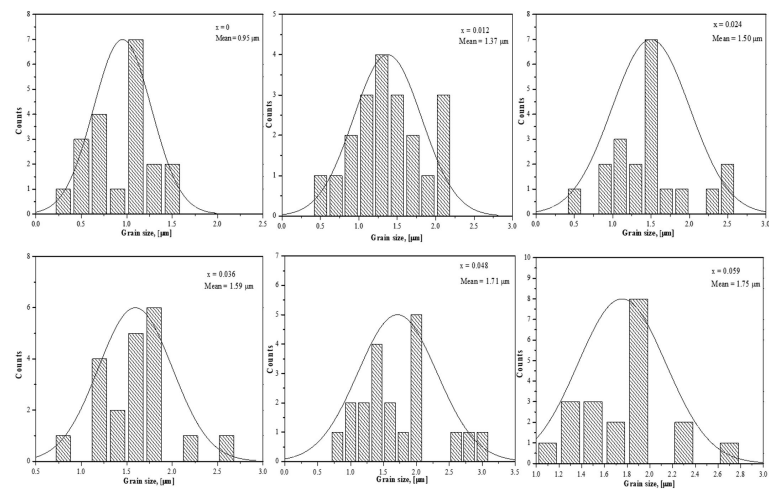

Fig. 6. Grain size distribution of the $\mathrm{Li}_{3+5 \mathrm{x}} \mathrm{Ta}_{1-\mathrm{x}} \mathrm{O}_{4}$ solid solution at $\times 5000$ magnification.

\subsection{Thermal and IR analyses}

Fig. 9 and Fig. 10 show TGA and DTA thermograms of the $\mathrm{Li}_{3+5 \mathrm{x}} \mathrm{Ta}_{1-\mathrm{x}} \mathrm{O}_{4}$ solid solution $(0 \leqslant$ $\mathrm{x} \leqslant 0.059)$ in the temperature range of $45{ }^{\circ} \mathrm{C}$ to $1000^{\circ} \mathrm{C}$. These materials are thermally stable as no thermal event is discernible throughout the studied temperature range. However, a negligible weight gain is observed at the starting temperature and this phenomenon is common for oxide ceramics. Occasionally, a weight gain which is observed might be due to the adsorption of gaseous substance. Meanwhile, the DTA thermograms of the $\mathrm{Li}_{3+5 \mathrm{x}} \mathrm{Ta}_{1-\mathrm{x}} \mathrm{O}_{4}$ solid solution $(0 \leqslant x \leqslant 0.059)$ also show neither 
Table 2. Summary of crystallite sizes, internal strain and grain sizes of the $\mathrm{Li}_{3+5 \mathrm{x}} \mathrm{Ta}_{1-\mathrm{x}} \mathrm{O}_{4}$ solid solution.

\begin{tabular}{lcccc}
\hline $\mathrm{x}$ & $\begin{array}{c}\text { Scherrer method } \\
{[\mathrm{nm}]}\end{array}$ & W-H method [nm] & Microstructure strain, $\epsilon$ & $\begin{array}{c}\text { Grain size, } \\
{[\mu \mathrm{m}]}\end{array}$ \\
\hline \hline 0 & 53 & 51 & 0.00013 & 0.95 \\
0.012 & 51 & 32 & 0.00028 & 1.37 \\
0.024 & 51 & 39 & 0.00035 & 1.50 \\
0.036 & 43 & 38 & 0.00050 & 1.59 \\
0.048 & 49 & 39 & 0.00048 & 1.71 \\
0.059 & 46 & 37 & 0.00065 & 1.75 \\
\hline
\end{tabular}

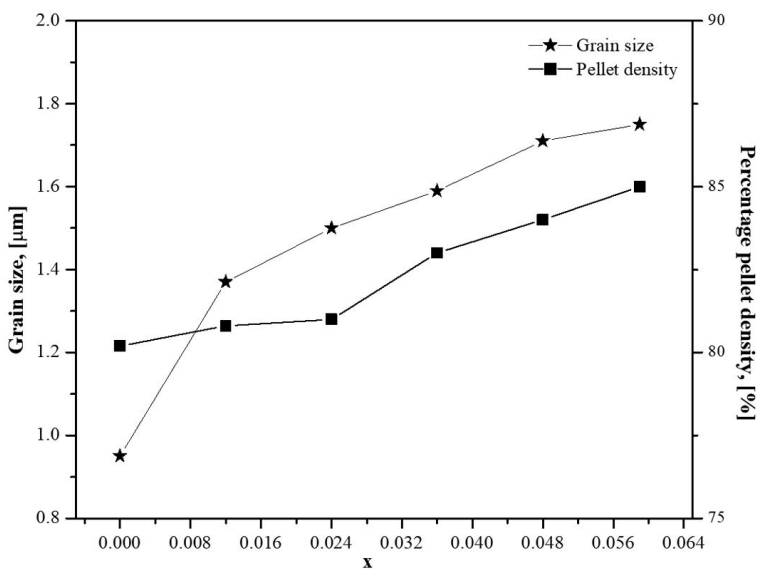

Fig. 7. Grain size and pellet densities of the $\mathrm{Li}_{3+5 \mathrm{x}} \mathrm{Ta}_{1-\mathrm{x}} \mathrm{O}_{4}$ solid solution as a function of $\mathrm{x}$.

endothermic nor exothermic peak over a heat-cool cycle.

Fig. 11 shows the FT-IR spectra of the $\mathrm{Li}_{3+5 \mathrm{x}} \mathrm{Ta}_{1-\mathrm{x}} \mathrm{O}_{4}$ solid solution $(0 \leqslant \mathrm{x} \leqslant 0.059)$ in the absorption range of $250 \mathrm{~cm}^{-1}$ to $1000 \mathrm{~cm}^{-1}$. Usually, inorganic solids tend to absorb infrared radiation in the low wavenumber region, which is typically below $1000 \mathrm{~cm}^{-1}$ at ambient temperature. The absorption bands observed at $\sim 800 \mathrm{~cm}^{-1}$ are attributed to the Ta-O-Ta vibrational mode [18]. Meanwhile, the stretching mode of the $\mathrm{Ta}-\mathrm{O}$ bond in the $\mathrm{TaO}_{6}$ octahedra is found at $\sim 580 \mathrm{~cm}^{-1}$ [19]. The absorption peaks at $\sim 360 \mathrm{~cm}^{-1}$ and $\sim 690 \mathrm{~cm}^{-1}$ could be assigned to the Ta-O stretching and vibration modes in the crystal structure $[20,21]$. The bands at $455 \mathrm{~cm}^{-1}$ and $260 \mathrm{~cm}^{-1}$ correspond to the specific vibration of $\mathrm{Li}-\mathrm{O}$ bond [22] and the $\mathrm{Li}-\mathrm{O}$ stretching [20],
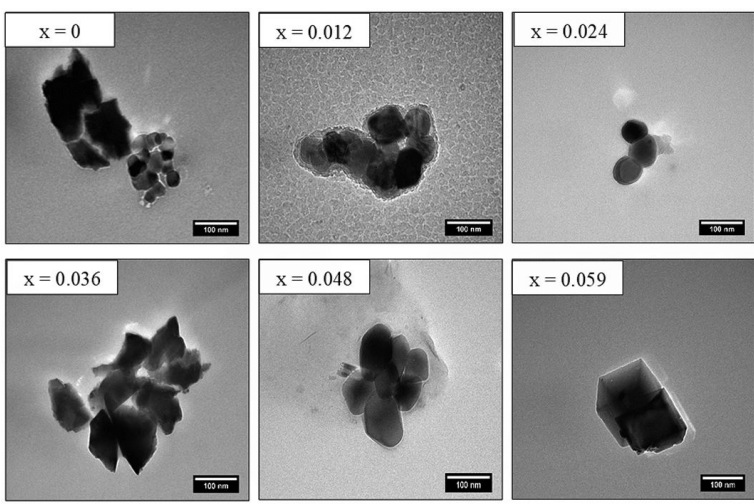

Fig. 8. TEM micrographs of the $\mathrm{Li}_{3+5 \mathrm{x}} \mathrm{Ta}_{1-\mathrm{x}} \mathrm{O}_{4}$ solid solution $(0 \leqslant x \leqslant 0.059)$ at $1000 \times$ magnification.

respectively. The summary of the observed absorption modes is tabulated in Table 3.

\subsection{Ionic conductivity}

Fig. 12 shows the Nyquist plots of the $\beta$ $\mathrm{Li}_{3} \mathrm{TaO}_{4}$ at different temperatures. At $200{ }^{\circ} \mathrm{C}$, the plot for $\beta-\mathrm{Li}_{3} \mathrm{TaO}_{4}$ is a nearly perfect semicircle without any spike at low frequency. The conductivity values of these materials have been extracted from the high intercepts of the plots, i.e. $Z^{\prime \prime}$ equals to zero using a complex impedance formalism, $Z^{*}$ $=Z^{\prime}-\mathrm{j} Z^{\prime \prime}$, where $Z^{\prime}$ and $Z^{\prime \prime}$ represent the real and imaginary parts of impedance component [23]. The semicircle becomes smaller and shifts to the lower $\mathrm{Z}^{\prime}$ values at elevated temperatures, thus indicating a decrease in the bulk resistance of the sample. It is not clear at this stage whether the electrical conduction is associated either with the intra-granular (bulk) or inter-granular (grain boundary) region of 
Table 3. Fourier transform infrared spectra of the $\mathrm{Li}_{3+5 \mathrm{x}} \mathrm{Ta}_{1-\mathrm{x}} \mathrm{O}_{4}$ solid solution.

\begin{tabular}{lcccccc}
\hline \multirow{2}{*}{ Mode } & \multicolumn{7}{c}{$\mathrm{x}$} \\
\cline { 2 - 7 } & 0 & 0.012 & 0.024 & 0.036 & 0.048 & 0.059 \\
\cline { 2 - 7 } & 801 & 800 & 802 & 799 & 802 & 801 \\
\hline \hline Vibration Ta-O-Ta & 692 & 691 & 690 & 688 & 693 & 693 \\
Vibration Ta-O & 585 & 583 & 587 & 584 & 590 & 589 \\
Stretching Ta-O bond in $\mathrm{TaO}_{6}$ & 456 & 456 & 464 & 456 & 466 & 456 \\
Vibration Li-O & 362 & 361 & 365 & 355 & 359 & 358 \\
Stretching Ta-O & 265 & 263 & 260 & 260 & 276 & 259 \\
Stretching Li-O & & & & & & \\
\hline
\end{tabular}

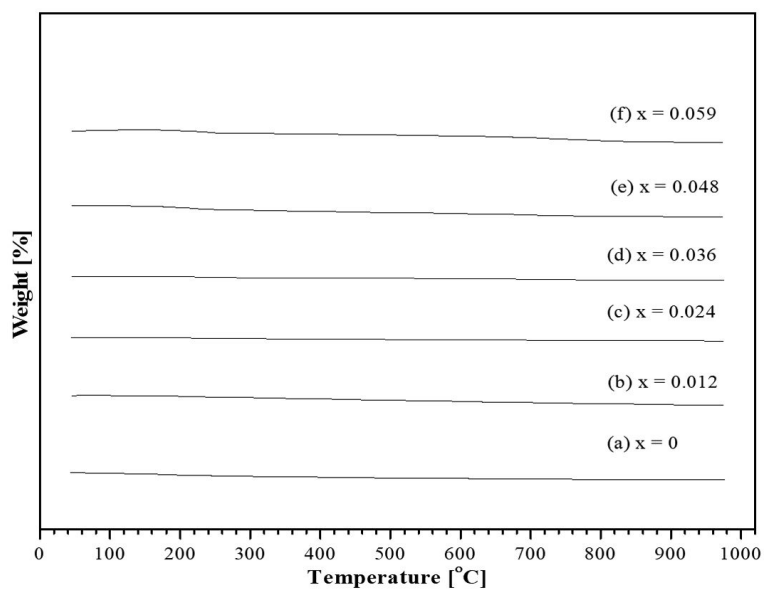

Fig. 9. TGA thermograms of the $\mathrm{Li}_{3+5 \mathrm{x}} \mathrm{Ta}_{1-\mathrm{x}} \mathrm{O}_{4}$ solid solution $(0 \leqslant x \leqslant 0.059)$.

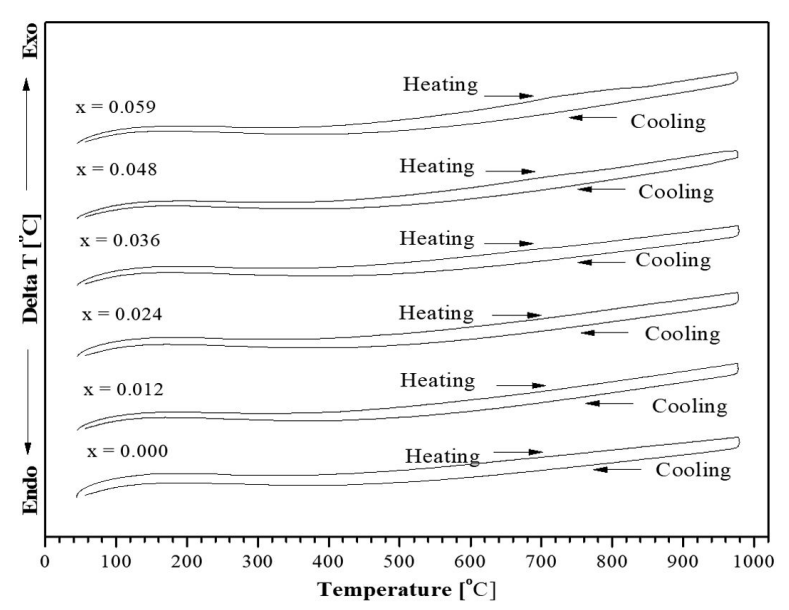

Fig. 10. DTA thermograms of the $\mathrm{Li}_{3+5 \mathrm{x}} \mathrm{Ta}_{1-\mathrm{x}} \mathrm{O}_{4}$ solid solution $(0 \leqslant \mathrm{x} \leqslant 0.059)$.

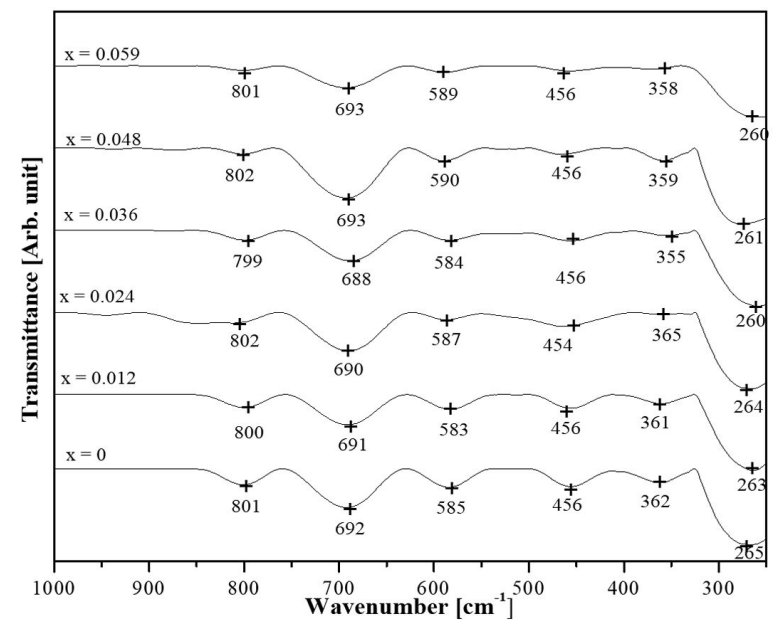

Fig. 11. FT-IR spectra of the $\mathrm{Li}_{3+5 \mathrm{x}} \mathrm{Ta}_{1-\mathrm{x}} \mathrm{O}_{4}$ solid solution $(0 \leqslant x \leqslant 0.059)$.

the sample. The associated capacitance at the maximum point of the semicircle of the $\beta-\mathrm{Li}_{3} \mathrm{TaO}_{4}$ at $200{ }^{\circ} \mathrm{C}$ has a value of $5.01 \times 10^{-12} \mathrm{~F} \cdot \mathrm{cm}^{-1}$ at $\omega_{\max } \mathrm{RC}=1$, which depicts a typical bulk response of a material [24]. Hence, the electrical response could be modelled by equivalent $\mathrm{RC}$ elements that are arranged in parallel (inset of Fig. 12a (i)).

At $250{ }^{\circ} \mathrm{C}$, the Nyquist plot of the $\beta-\mathrm{Li}_{3} \mathrm{TaO}_{4}$ portrays a semicircular arc with a spike in the lower frequency region. The spike is associated with the blocking electrode effect, which is due to the blocking ions at the sample-electrode interfacial region. This also confirms that lithium ions are the conducting species within the sample. The high frequency semicircle has an associated capacitance of $5.08 \times 10^{-12} \mathrm{~F} \cdot \mathrm{cm}^{-1}$, which is the bulk response. Meanwhile, the spike at low frequency has a ca- 
pacitance of the order of $\sim 10^{-9} \mathrm{~F} \cdot \mathrm{cm}^{-1}$, which is due to the double layer capacitance, $\mathrm{C}_{\mathrm{dl}}$. Such a phenomenon serves to show an evidence of ions migration at the electrode-electrode interface [25]. Hence, an additional $\mathrm{C}$ element, $\mathrm{C}_{\mathrm{dl}}$ is required and added in series to the parallel $\mathrm{RC}$ elements in order to model the electrical response (inset of Fig. 12a (ii)). In other words, the magnitude of the blocking double-layer capacitance could be assessed from any position on the spike $\left(Z^{\prime \prime}=1 / 2 \pi f C\right)$.

As temperature increases, the semicircular arc representing the bulk electrical response is gradually diminished and replaced by a single spike as shown in Fig. 12b. It shows clearly the characteristic of ionic polarization phenomena at the blocking electrodes and the limited diffusion of Warburg impedance, thus supporting the idea that the electrical conduction is predominantly ionic [24]. The angle of the electrode spikes is less than an ideal $90^{\circ}$, which may be due to the gold electrodes that are partially blocked by $\mathrm{Li}^{+}$ions at elevated temperatures [26].

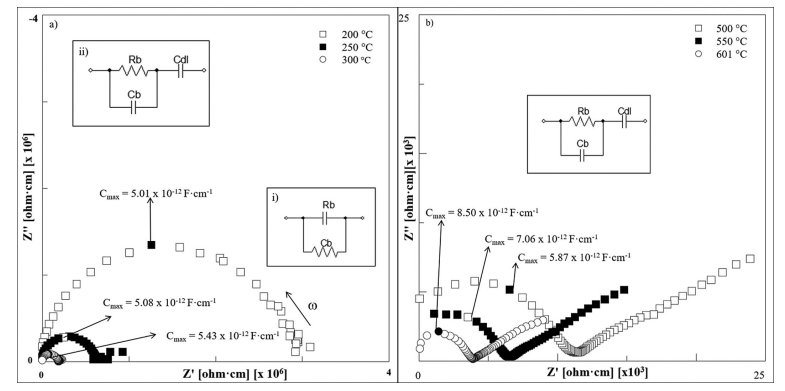

Fig. 12. Nyquist plots of the (a) $\mathrm{Li}_{3} \mathrm{TaO}_{4}$ at $200{ }^{\circ} \mathrm{C}$, $300{ }^{\circ} \mathrm{C}$ and $350{ }^{\circ} \mathrm{C}$ (b) $\mathrm{Li}_{3} \mathrm{TaO}_{4}$ at $500{ }^{\circ} \mathrm{C}$, $550{ }^{\circ} \mathrm{C}$ and $601{ }^{\circ} \mathrm{C}$.

On the other hand, Fig. 13 shows the Nyquist plots of the $\mathrm{Li}_{3+5 \mathrm{x}} \mathrm{Ta}_{1-\mathrm{x}} \mathrm{O}_{4}$ solid solution $(0 \leqslant \mathrm{x}$ $\leqslant 0.059)$ at $350{ }^{\circ} \mathrm{C}$. The electrical conductivities of the samples are found to decrease with increasing lithium content. This is probably due to the elimination of empty sites that are required by the interstitial $\mathrm{Li}^{+}$to jump between the neighboring sites. In general, the ionic conductivity of a material would increase if there were more available empty sites with a similar potential energy and the energy barrier was sufficiently low [27].
The combined spectroscopic plots of the imaginary part of modulus, $\mathrm{M}^{\prime \prime}$ and the imaginary part of impedance, $Z^{\prime \prime}$ are particularly useful and could be used to determine the electrical homogeneity of ceramics. In general, the bulk-type regions dominate the $\mathrm{M}^{\prime \prime}$ spectra due to the lower capacitance, while the thin layer-type regions dominate the $Z^{\prime \prime}$ spectra due to the higher capacitance and resistive components [25]. Fig. 14 shows two overlapping peaks that are almost coincident at $300{ }^{\circ} \mathrm{C}$ and the full width at half maximum (FWHM) of the $\mathrm{M}^{\prime \prime}$ peak has a value of $\sim 1.15$ decades on a logarithmic scale of frequency. Such a value is close to the perfect Debye response of 1.14 decades, thus suggesting the $\beta-\mathrm{Li}_{3} \mathrm{TaO}_{4}$ is electrically homogeneous [28].

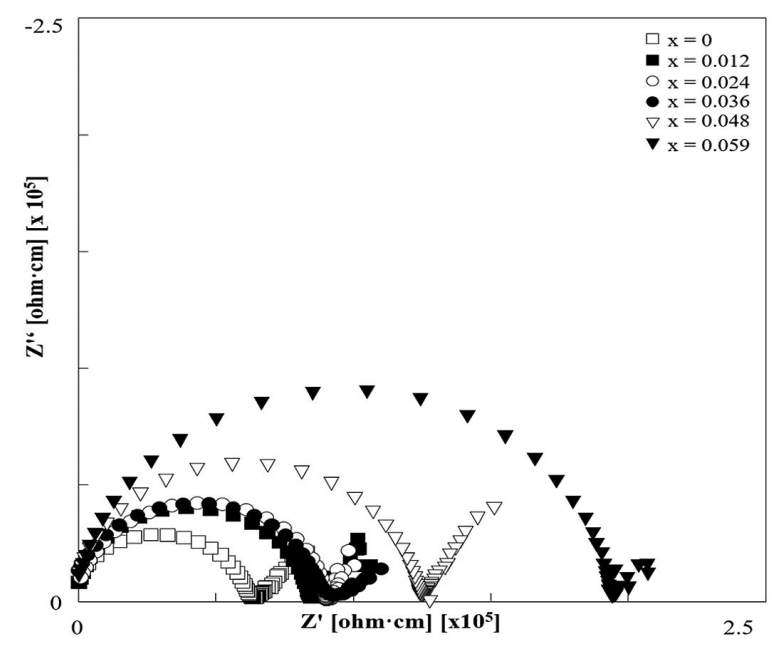

Fig. 13. Nyquist plots of the $\mathrm{Li}_{3+5 x} \mathrm{Ta}_{1-\mathrm{x}} \mathrm{O}_{4}$ solid solution at $350{ }^{\circ} \mathrm{C}$.

The Arrhenius law is commonly used to show the correlation between the conductivity and temperature. It can be represented by a formula, $\sigma=$ $\sigma_{0} \exp \left(-\mathrm{E}_{\mathrm{a}} / \mathrm{kT}\right)$, where $\sigma_{0}$ is the pre-exponential factor, $E_{a}$ is the apparent activation energy of the conduction process, $\mathrm{k}$ is Boltzmann constant and $\mathrm{T}$ is the absolute temperature. The bulk conductivity values in the range of $10^{-6} \Omega^{-1} \cdot \mathrm{cm}^{-1}$ to $10^{-3} \Omega^{-1} \cdot \mathrm{cm}^{-1}$ have been determined from the AC impedance data from $200{ }^{\circ} \mathrm{C}$ to $850{ }^{\circ} \mathrm{C}$. The Arrhenius conductivity plots show that the electrical responses of these materials are reversible on both heat-cool cycles. In addition, the linear plots with a single gradient suggest that there is 


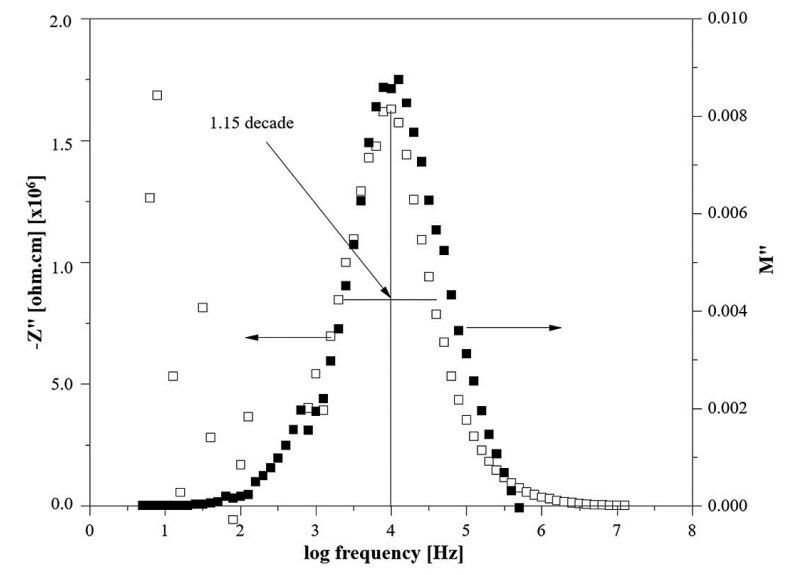

Fig. 14. Combined spectroscopic plots of $Z^{\prime \prime}$ and $\mathrm{M}^{\prime \prime}$ of the $\mathrm{Li}_{3} \mathrm{TaO}_{4}$ as a function of frequency at $300{ }^{\circ} \mathrm{C}$.

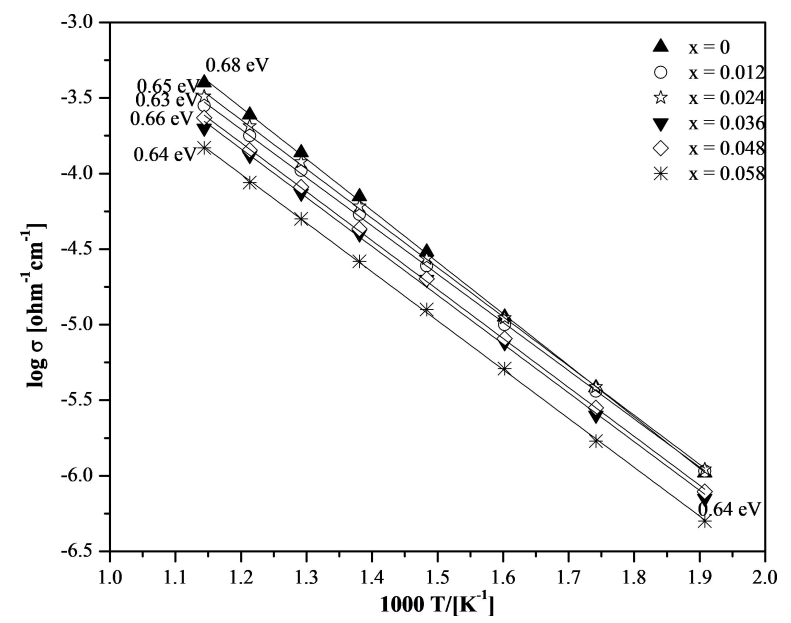

Fig. 15. Conductivity Arrhenius plots of the $\mathrm{Li}_{3+5 \mathrm{x}} \mathrm{Ta}_{1-\mathrm{x}} \mathrm{O}_{4}(0 \leqslant \mathrm{x} \leqslant 0.059)$ samples.

no systematic deviation as a function of temperature; i.e. long-range Debye-Huckel interaction or the complexes formed by short-range attraction [15]. These results are well supported by the DTA results of the $\mathrm{Li}_{3+5 \mathrm{x}} \mathrm{Ta}_{1-\mathrm{x}} \mathrm{O}_{4}(0 \leqslant \mathrm{x} \leqslant$ $0.059)$ solid solution especially there is no thermal event found. The activation energies of the $\mathrm{Li}_{3+5 \mathrm{x}} \mathrm{Ta}_{1-\mathrm{x}} \mathrm{O}_{4}$ solid solution $(0 \leqslant \mathrm{x} \leqslant 0.059)$, as calculated from the gradients, are relatively low and their values are found to be in the range of $0.63 \mathrm{eV}$ to $0.68 \mathrm{eV}$ (Fig. 15). The summary of the bulk resistivities, $R_{b}$ and conductivities, $\sigma$ of the $\mathrm{Li}_{3+5 \mathrm{x}} \mathrm{Ta}_{1-\mathrm{x}} \mathrm{O}_{4}$ solid solution $(0 \leqslant \mathrm{x} \leqslant 0.059)$ at different temperatures are tabulated in Table 4.
As a comparison, the ionic conductivity of the undoped $\beta-\mathrm{Li}_{3} \mathrm{TaO}_{4}$ is found to be relatively higher than that of other related phases. The conductivity of the $\beta-\mathrm{Li}_{3} \mathrm{TaO}_{4}$ is about two orders of magnitude higher than that of the $\mathrm{LiTaO}_{3}$ with their recorded values of $1.82 \times 10^{-3} \Omega^{-1} \cdot \mathrm{cm}^{-1}$ and $1.08 \times 10^{-5}$ $\Omega^{-1} \cdot \mathrm{cm}^{-1}$ at $300^{\circ} \mathrm{C}$, respectively [24]. However, both phases have rather similar activation energies, i.e. $0.63 \mathrm{eV}$ and $0.60 \mathrm{eV}$, respectively. On the other hand, the $\mathrm{Li}_{2} \mathrm{TiO}_{3}$ was reported to have a similar order of the conductivity value of $\sim 10^{-6}$ $\Omega^{-1} \cdot \mathrm{cm}^{-1}$ at $300{ }^{\circ} \mathrm{C}$ and activation energy, i.e. $0.60 \mathrm{eV}$. Among these related phases, the $\mathrm{Li}^{+}$ions are proposed to be the major charge carrier, which could be due to its highly mobile behavior [24, 29].

Table 4. Summary of the ionic conductivities, $\sigma$ and activation energies, $\mathrm{Ea}$ of the $\mathrm{Li}_{3+5 \mathrm{x}} \mathrm{Ta}_{1-\mathrm{x}} \mathrm{O}_{4}$ solid solution at different temperatures.

\begin{tabular}{cccccc}
\hline $\left.\begin{array}{c}\text { Bulk conductivity } \\
\sigma\end{array} \times 10^{-5} \Omega^{-1} \cdot \mathrm{cm}^{-1}\right]$ & 250 & 300 & 400 & 500 & energy $[\mathrm{eV}]$ \\
\hline \hline 0 & 0.17 & 0.57 & 3.02 & 13.8 & 0.68 \\
0.012 & 0.17 & 0.38 & 2.45 & 10.5 & 0.66 \\
0.024 & 0.11 & 0.39 & 2.75 & 12.0 & 0.65 \\
0.036 & 0.11 & 0.39 & 2.00 & 7.41 & 0.64 \\
0.048 & 0.11 & 0.36 & 2.01 & 8.13 & 0.63 \\
0.059 & 0.05 & 0.16 & 1.25 & 5.01 & 0.64 \\
\hline
\end{tabular}

\section{Conclusion}

The rock-salt structured $\beta-\mathrm{Li}_{3} \mathrm{TaO}_{4}$ solid solution prepared by solid-state reaction showed interesting bulk electrical response with an associated capacitance of the order of $\sim 10^{-12} \mathrm{~F} \cdot \mathrm{cm}^{-1}$. At intermediate temperature from $200{ }^{\circ} \mathrm{C}$ to $850{ }^{\circ} \mathrm{C}$, the $\mathrm{Li}_{3+5 \mathrm{x}} \mathrm{Ta}_{1-\mathrm{x}} \mathrm{O}_{4}$ solid solutions showed moderate oxide ion conductivities in the range of $10^{-6}$ $\Omega^{-1} \cdot \mathrm{cm}^{-1}$ to $10^{-3} \Omega^{-1} \cdot \mathrm{cm}^{-1}$. Their ionic conductivities were found to decrease with increasing Li content and this could be explained by the limited empty sites available for jumping ions to the neighboring sites. 


\section{Acknowledgements}

We appreciate the financial support from the Ministry of Higher Education, Malaysia, via the High Impact Putra Grant (GPB).

\section{References}

[1] Janot R., GuÉrard D., Prog. Mater. Sci., 50, (2005), 1.

[2] Thangadurai V., Weppner W., Ionics, 8, (2002), 281.

[3] El-Metwaly F.G., Abou-Sekkina M.M., SaAd F.A., KHedR A.M., Mater. Sci.-Poland, 4, (2014), 571.

[4] Zainuddin L.W., Kamarulzaman N., Adv. Mater. Res., 545, (2012), 275.

[5] Biswas S.P., TANGri R.P., Prasad R., Suri A.K., T. Indian Ceram. Soc., 59, (2000), 88.

[6] Blasse G., Z. Anorg. Allg. Chem., 331, (1964), 44.

[7] Zhou D., WANG H., PANG L-X., Yao X., WU X-G., Am. Ceram. Soc. Bull., 91, (2008), 4115.

[8] Boulay D., Sakaguchi D.A., Ishizawa K., Sud A., Nobu O., Acta Crystallogr. C, 59, (2003), 80.

[9] Zocchi M., Gatтi M., J. Solid State Chem., 48, (1983), 420.

[10] Zocchi M., Gatti M., Santoro A., Roth R.S., J. Solid State Chem., 53, (1984), 277.

[11] Martel L.C., Roth R.S., Am. Ceram. Soc. Bull., 60, (1981), 376

[12] Deqiong Z., Shuming P., Xiaojun C., Xialing G., TongZAI, J. Nucl. Mater, 396, (2010), 245.

[13] Glass A.M., Nassau K., Negran T.J., J. Appl. Phys., 49, (1978), 4808.

[14] Miao C.R., Torardi C.C., J. Solid State Chem., 145, (1999), 110.

[15] West A.R., Solid State Chemistry and It Applications, John Wiley \& Sons, Ltd, New Jersey, 1999.
[16] Yogamalar R., Mahendran V., Srinivasan R., Beitollahi A., Kumar R.P., Bose A.C., Vinu A., Chem. Asian J., 5, (2010), 2379.

[17] Khanfekr A., Tamizifar M., NaghizadeH R., Mater. Sci.-Poland., 32, (2014), 430.

[18] Chon M.P., Tan K.B., Khaw C.C., Zainal Z., YaP Y.H.T., ChEN S.K., TAN P.Y., J. Alloy. Compd., 590, (2014), 479.

[19] WaChs E.I., BRiand L.E., JEHng J-M., BurChaM L., Gao X., Catal. Today., 57, (2000), 323.

[20] Zhang J-Y., Fang Q., Boyd I.W., Appl. Surf. Sci., 138, (1999), 320.

[21] Ono H., Hosokawa Y., Shinoda K., Koyanagi K., Yamaguchi H., Thin Solid Films., (2001), 57.

[22] Jie Z., Dongxu L., Wei D., Zeyan W., Peng W., Hefeng C., Baibiao H., Minhua J., J. Cryst. Growth., 318, (2011), 1121.

[23] Kashif. I., Soliman A.A., Sakr E.M., RateP A., Spectrochim Acta A, 113, (2013), 15.

[24] BAK K.Y., TAN K.B., KhaW C.C., Zainal Z., TAN P.Y., ChOn M.P., Sains Malays., 43, (2014), 1573.

[25] Irvine J.T.S., Sinclair D.C., West A.R., $A d v$. Mater., 2, (1990), 132.

[26] Mclaren V.L., Kirk C.A., Poisot M., CastelLANos M., WeSt A.R., Dalton T., 19, (2004), 3042.

[27] Sinclair, D.C., Bol. Soc. Esp. Cerám. V., 34, (1995), 55.

[28] Ziman, J.M., Electrons and phonons. Oxford University Press, London, 1960.

[29] Dash U., Sahoo S., Parashar S.K.S., ChaudHURI P., J. Adv. Ceram., 3, (2014), 98. 